\title{
Conversion and Separation of Bamboo Lignocellulosic Components
}

\author{
Hao REN and Masamitsu FUNAOKA \\ Graduate School of Bioresources, Mie University, 1577 Kurima-machiya, Tsu, Mie, 514-8507, Japan \\ Tel: +81-59-231-9521 Fax: +81-59-231-9517 E-mail: Funaoka@bio.mie-u.ac.jp
}

\begin{abstract}
The conversion and separation patterns of bamboo lignocellulosics through the phase-separation system were investigated. Through short term phase-separation treatment without ultrasonic irradiation, bamboo lignocellulosics were separated into carbohydrates and ligno- $p$-cresols more rapidly than woody materials. There is no difference in the separation pattern between with and without ultrasonic irradiation. The ${ }^{\mathrm{l}} \mathrm{H}-\mathrm{NMR}$, FT-IR, pyrolysis GC/MS and TMA analytical data indicated that the characteristics of bamboo ligno- $p$-cresols were basically similar to hardwood ligno- $p$-cresols. However, a part of $p$-coumaric acid esterified to native core lignins remained in the lignin molecule even after phase-separation treatment, due to solvation effect with cresol. Bamboo ligno-p-cresols had high protein-adsorption capacities, comparable to wood ligno-p-cresols, which were 5 10 times higher than conventional lignin preparations.
\end{abstract}

Key words: bamboo, lignin, the phase-separation system, ligno-p-cresols

\section{INTRODUCTION}

Lignin is an aromatic polymer found in all vascular plants. Currently, it is produced as a by-product of paper industry, and burned for its fuel value. When petroleum feedstock was cheap, it was not focused to recovering as a chemical feedstock. Today, petroleum feedstock is becoming scarcer and more expensive, and an ever increasing percentage comes from nonpetroleum sources. It is time to consider this domestic, renewable feedstock, lignin as a source of aromatics compounds [1].

With the exception of cellulose there is not a more abundant renewable natural resource than lignin, a polyphenolic macromolecule present in the cell wall of plants. Lignin is created by enzymatic polymerization of three monomers, coniferyl alcohol, synapyl alcohol and $p$-coumaryl alcohol [2]. The resulting structure is a complex macromolecule with a great variety of functional groups and over 10 different types of linkages. Depending on the original sources and extraction methods used, the physico-chemical characteristics of lignins, and thus their suitability to be used in polymer formulations, can vary noticeably.

Through short term phase-separation treatment without ultrasonic irradiation, bamboo lignocellulosics (Phyllostachys bambusoide, Phyllostachys heterocycl, Phyllostachys nigra) were separated into carbohydrates and ligno-p-cresols more rapidly than woody materials $[3,4,5]$. In this work, the conversion and separation characteristics of bamboo lignocellulosics components were discussed, with and without ultrasonic irradiation

2. EXPERIMENTAL

\subsection{Materials}

Internodal pieces of bamboo were mechanically liberated from the epidermis, cut into short rings (about $1 \mathrm{~cm}$ in length) and reduced to small pieces. Air dried bamboo chips were ground successively in a Wiley mill and a vibrational mill to pass an 80 mesh screen, and extracted with ethanol-benzene $(1: 2, \mathrm{v} / \mathrm{v})$ for $48 \mathrm{hr}$. 


\subsection{Synthesis and isolation of ligno-p-cresols}

Synthesis and isolation of ligno- $p$-cresols were carried out with the previous method [3]. To enhance the efficiency of the phase-seperation reaction, the reaction mixture was irradiated by ultrasound $(20 \mathrm{KHz}$, $180 \mathrm{~W})[6,7]$. The yields and structural characteristics of the resulting bamboo lignophenols with and without ultrasonic irradiation were compared.

\subsection{Physicochemical characterization of} ligno-p-cresols

The characteristics of bamboo lignophenols were analyzed by ${ }^{1} \mathrm{H}-\mathrm{NMR}$, FT-IR, TMA [5], and pyrolysis gas chromatography/mass spectrometry (Py-GC/MS). $P y-G C / M S$ conditions: Samples were pyrolyzed in a quartz holder at $500^{\circ} \mathrm{C}$ for $12 \mathrm{~s}$, using a Pt-coil pyrolyzer coupled to a gas chromatograph interfaced to an ion trap detector (ITD). The gas chromatograph was fitted with a crosslinked methyl silicone capillary column (Quardrex S 2006; 0.25mmI.D. $\times 50 \mathrm{~m}$ length $\times 0.25 \mu 1$ film thickness programmed from $90^{\circ} \mathrm{C}$ with temperature rising speed $4{ }^{\circ} \mathrm{C} / \mathrm{min}$ to $500^{\circ} \mathrm{C}$, holding the initial temperature for $1 \mathrm{~min}$.

2.4 Determination of the protein-adsorbing capacities of bamboo lignophenols

Ligno- $p$-cresols $(10 \mathrm{mg}$ ) were suspended in $0.5 \mathrm{~mL}$ of acetate buffer solution ( $\mathrm{pH} 4.5$ ). A $0.5 \mathrm{~mL}$ of bovine serum albumin (BSA) solutions $(2 \mathrm{mg} / \mathrm{mL})$ was added to the suspension, and stirred at $20{ }^{\circ} \mathrm{C}$ for $1 \mathrm{hr}$. The resulting lignin-protein complex were centrifuged and filtrated, and then free BSA in the supernatant solution was determined by the Bradford method [18]. Adsorbed BSA was calculated by subtracting the BSA in the supernatant solution from the BSA added.

\section{RESULTS AND DISCUSSION}

\subsection{Yields of ligno-p-cresols with ultrasonic irradiation}

The separation of lignin and carbohydrates from three kinds of bamboo through the phase-separation system was quicker than those of the softwood and hardwood samples in previous examinations, and for all three kinds of bamboo the yield of ligno- $p$-cresols indicated the maximum value in 10-20 minutes [5] .

In the condition of total reaction time $5 \mathrm{~min}$ and
(1) Total reaction time: $10 \mathrm{~min}$
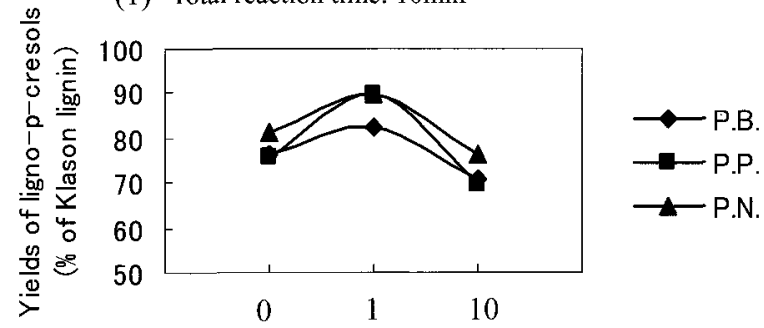

Ultrasonic irradiation time $(\mathrm{min})$

(2) Total reaction time: $5 \mathrm{~min}$
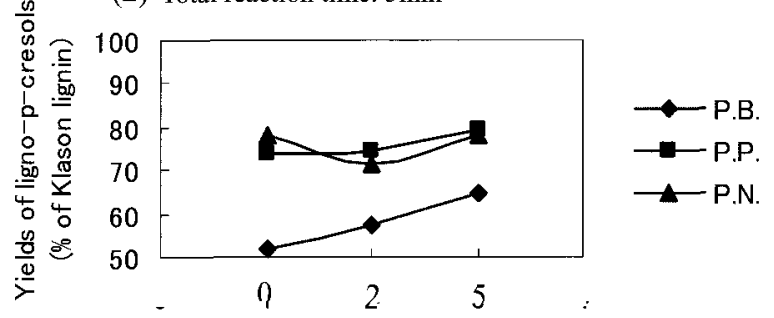

Ultrasonic irradiation time ( $\mathrm{min}$ )

Fig.1 Yields of bamboo ligno-p-cresols

$10 \mathrm{~min}$, the yields of ligno- $p$-cresols were compared with and without ultrasonic irradiation (Fig.1). In the case of total reaction time $10 \mathrm{~min}$, only 1 min irradiation show a little yields up, and when the irradiation time was extended to $10 \mathrm{~min}$, the yields showed a few lower than the without irradiation case. Because that a part of low molecular ligno-p-cresols had been lost as ether soluble components during the refinement process. It was also observed that for the phase separation treatment of bamboo in reaction time $5 \mathrm{~min}$ is insufficient. No distinguish changes had been found in yields between with and without ultrasonic irradiation through $5 \mathrm{~min}$. That is, through the phase-separation treatment, the conversion pattern of bamboo differs from softwood, which showed a distinguish efficiency up with ultrasonic irradiation [6]. This originates in a structural characteristic with loose structure in bamboo cell wall, vascular bundle is scattered and its secondary enlargement is different from wood materials $[8,9,10]$

3.2 Comparison for Structure characteristics of bamboo ligno-p-cresols resulted with and without ultrasonic irradiation

\section{FT-IR spectra}

In Fig.2 FT-IR spectra of three kinds of bamboo ligno-p-cresols resulted with ultrasonic irradiation are shown. No differences have been found compared to the samples received without ultrasonic irradiation [5]. 


\section{Amounts of combined p-cresols}

The amount of combined $p$-cresols in bamboo ligno-p-cresols are almost in the same frequency $\left(0.74 \sim 0.76 \mathrm{~mol} / \mathrm{C}_{9}\right)$ with and without ultrasonic irradiation. It is different from the softwood case with ultrasonic irradiation $\left(0.73 \mathrm{~mol} / \mathrm{C}_{9}[5 \mathrm{~min}], 0.95 \mathrm{~mol} / \mathrm{C}_{9}\right.$ [20 $\mathrm{min}])[5,6]$.

\section{$\underline{T M A}$ analysis of ligno-p-cresols}

The phase transition points of bamboo ligno- $p$-cresols resulted with ultrasonic irradiation showed the same pattern with those resulted without ultrasonic irradiation[5]. That is to say, the structural characteristics of bamboo ligno-p-cresols are stable even in the case of adding energy to the reaction system.

\section{$\underline{P y-G C / M S \quad \text { spectra }}$}

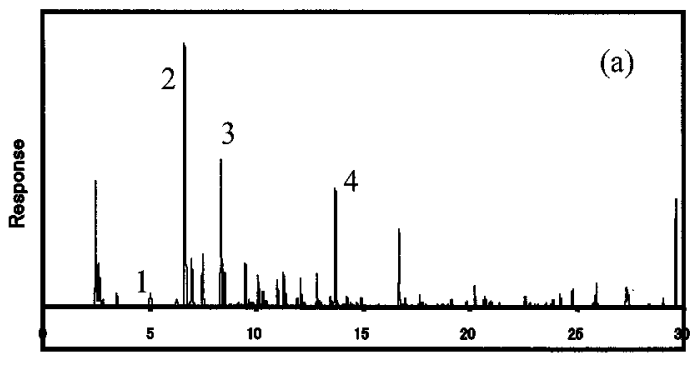

Retention time ( $\mathrm{min}$ )

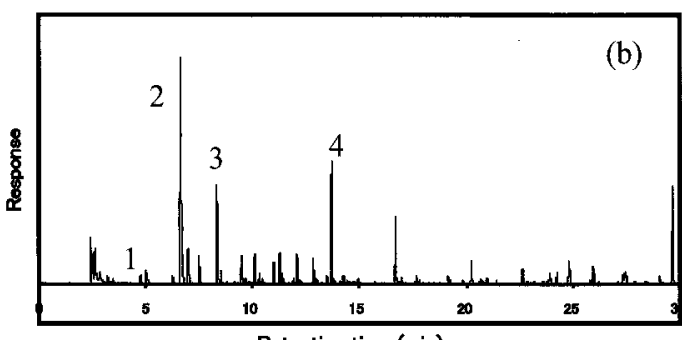

Retention timo (min)

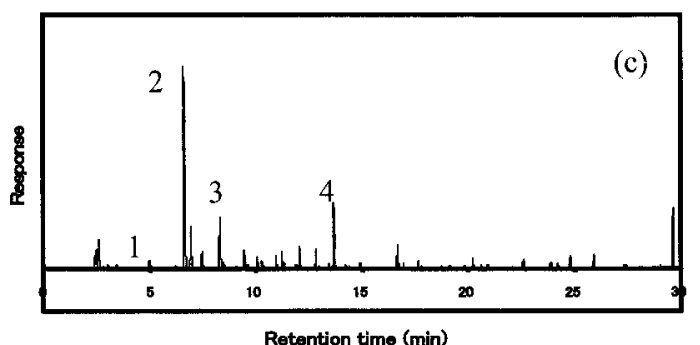

Fig.3 Py-GC/MS analysis of bamboo ligno-p-cresols

(a)Madake, (b)Mosotiku, (c)Hatiku.

Native lignin is an extremely complex three dimensional polymer (typically found in vascular plants) formed by dehydrogenative polymerization of $p$-hydroxycinnamyl, coniferyl and sinapyl alcohols.

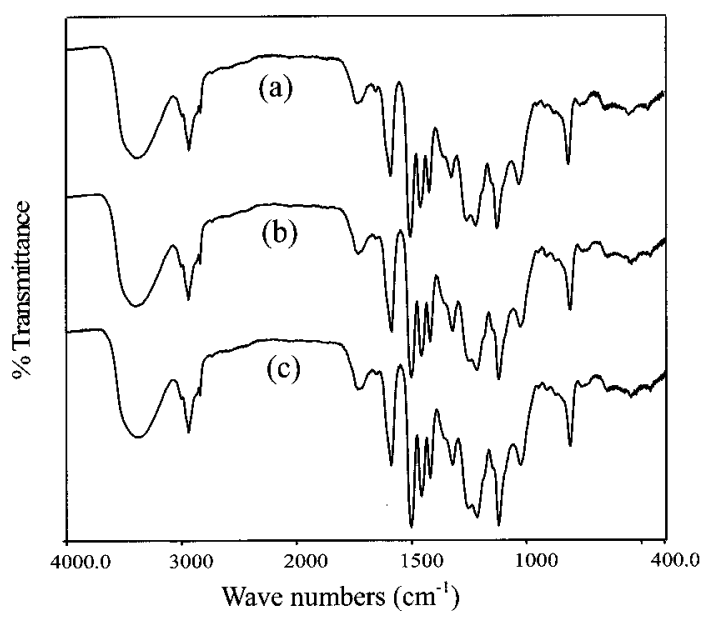

Fig.2 FT-IR spectra of bamboo ligno-p-cresols with ultrasonic irradiation (a) Madake, (b) Mosotiku, (c) Hatiku.

These three lignin precursors give rise to the so-called $\mathrm{H}$ (p-hydroxyphenyl), G (guaiacyl) and $\mathrm{S}$ (syringyl) phenylpropanoid units, which show different abundances in lignins from different groups of vascular plants, as well as in different plant tissues and cell-wall layers. In this study, Py-GC/MS was used to confirm exists of $\mathrm{H}$ units remained in bamboo ligno- $p$-cresols. As shown in Fig.3, for the three kinds of bamboo the peak of the phenol (peak $1, \mathrm{~m} / \mathrm{z}$ 94) that originated in $\mathrm{H}$ nucleus was admitted at about $5 \mathrm{~min}$. This resulted in the ester bond between core lignin and $\mathrm{H}$ units ( $p$-hydroxybenzoic acid etc.) which are easy to separate by thermolysis.

Moreover, the Py-GC/MS spectra of MWL and Klason lignin of bamboo had been reported $[12,13,14]$. It showed a very complex peak pattern. Compared to it, the Py-GC/MS spectra of bamboo lignophenols showed to having guaiacyl (peak 3, m/z 138, methylguaiacol) and syringyl (peak 4, m/z 168, methylsyringol). Besides them, another distinguish peak was observed (peak 2, $\mathrm{m} / \mathrm{z}$ 107). It was originated in grafted $p$-cresols. In briefly, the Py-GC/MS spectra of lingo-p-cresols were very simple. The main chain was composed of $\mathrm{G}, \mathrm{S}$ and grafted $\mathrm{H}$ units. This resulted in the different mechanism between preparing Klason lignin and lignophenols. For Klason lignin, many $\mathrm{C}-\mathrm{C}$ condensation type structures were generated when natural lignin were treated with a drastic acid condition. On the other hand, lignophenol 
was synthesized through the phase separation system, and the native lignin was protected by $p$-cresols and selectively converted into 1,1-bis-aryl-propane structure and concentration acid was only used as catalyst in this process. Under high energy conditions, the grafted $p$-cresol will be released firstly for its reactivity position. In addition, the released phenol nuclei by the end of $5 \mathrm{~min}$ resulted in the esterified $p$-hydroxyophenol units of bamboo ligno-p-cresols, which were accordant to the FT-IR and UV-vis data.

3.3 Determination of the protein-adsorbing capacities of fractionated ligno-p-cresols

Protein-adsorbing capacities of various kinds of lignin samples were examined. It was found that all of the samples tested have protein-adsorbing capacities and that, especially, lignophenols received from wood materials show higher protein-adsorption capacities, compared with other lignin preparations $[15,16]$. The maximum protein adsorption to ligno- $p$-cresols was achieved around the isoelectric points of proteins. The affinity of ligno- $p$-cresol from softwood for BSA was 5-10 times higher than those of conventional lignins, which containing kraft lignin, soda lignin, dioxane lignin, steam-explosion lignin etc.[17].The BSA adsorbing capacity of softwood (Westernhemlock), hardwood (Poplar) and bamboo(Madake) ligno-p-cresols per one gram are $60.43 \mathrm{mg}, 57.61 \mathrm{mg}$, $63.81 \mathrm{mg}$ respectively. These data indicated that bamboo ligno-p-cresols had high protein-adsorption capacities, comparable to wood ligno- $p$-cresols.

\section{CONCLUSIONS}

Bamboo lignocellulosics were separated into carbohydrates and ligno- $p$-cresols more rapidly than woody materials. There is no difference in the separation pattern between with and without ultrasonic irradiation. The characteristics of bamboo ligno- $p$-cresols were basically similar to hardwood ligno-p-cresols. However, a part of $p$-coumaric acid esterified to native core lignins remained in the lignin molecule even after phase-separation treatment, due to solvation effect with cresol. The structural characteristics are stable even under ultrasonic irradiation conditions. Again, bamboo ligno-p-cresols had high protein-adsorption capacities, comparable to wood ligno-p-cresols, which were 5 10 times higher than conventional lignin preparations.

\section{REFERENCES}

[1] H.J.P. Parkhurst, D.T.A. Jr.,Huibers, M.W. Jones, ACS.Div.Pet.Chem., 19, 229-244 (2000).

[2] E. Sjöström, Wood Chemistry Fundamentals and Applications, 4, 71-86 (1993).

[3] M. Funaoka and I. Abe, Tappi Journal, August, 145-149 (1989).

[4] M. Funaoka and S. Fukatsu, Holzforschung, 50, 245-252 (1996).

[5] H. Ren and M. Funaoka, Trans.MRS-J., in press (2007).

[6] K. Nagamatsu, Y. Nagamatsu, M. Funaoka, Networkpolymer, 24 (1), 30-39 (2003).

[7] S. Goskonda, W. J. Catallo, T. Junk, Waste Management, 22, 351-356 (2002).

[8] T.Y. Lo, H.Z. Cui, H.C. Leung, Materials Letters, 58, 2595-2598 (2004).

[9] S. Amada, U.T. Sun, Composites: Part B, 32, 451-459 (2001).

[10] B. Lybeer, G. Koch, J.V. Acker, P. Goetghebeur, Annals of Botany, 97(4), 529-539 (2006).

[11] T. Higuchi, M. Tanahashi, and A. Sato, Mokuzai Gakkaishi, 18(4), 183-189 (1972).

[12] M. Shimada, Wood research, 53, 19-65 (1972).

[13] R. Brezny, V. Mihalov, V. Kovacik, Holzforschung, 37, 199-204 (1983).

[14] M. Kawamoto, F. Nakatsubo, and K. Murakami, Mokuzai Gakkaishi, 38 (1), 81-84 (1992).

[15] E. Haslam, Biochem.J., 139 , 285-288 (1974).

[16] M. Funaoka, Polymer International, 47, 277-290 (1998).

[17] M.M. Bradford, Analytical Biochemistry, 72, 248-254 (1976).

(Recieved June 6, 2008 ; Accepted September 5, 2008) 